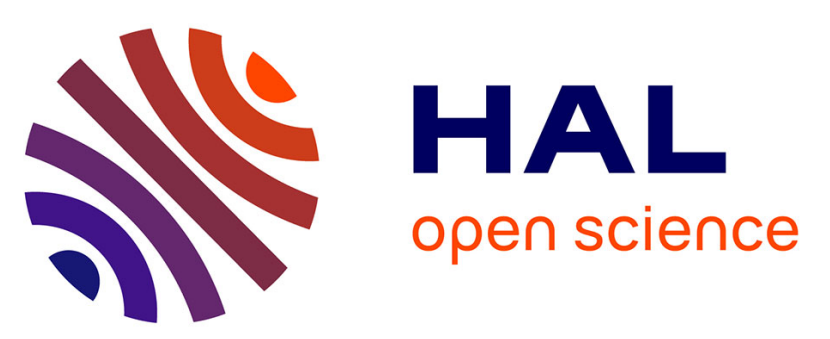

\title{
Epidemiology and clinical presentation of gonorrhoea in England \& Wales: Findings from the Gonococcal Resistance to Antimicrobials Surveillance Programme 2001-2006
}

\author{
Valerie Delpech, Iona M C Martin, Gwenda Hughes, Tom Nichols, Laura
} James, Catherine A Ison

\section{To cite this version:}

Valerie Delpech, Iona M C Martin, Gwenda Hughes, Tom Nichols, Laura James, et al.. Epidemiology and clinical presentation of gonorrhoea in England \& Wales: Findings from the Gonococcal Resistance to Antimicrobials Surveillance Programme 2001-2006. Sexually Transmitted Infections, 2009, 85 (5), pp.317. 10.1136/sti.2008.034843 . hal-00552806

\section{HAL Id: hal-00552806 https://hal.science/hal-00552806}

Submitted on 6 Jan 2011

HAL is a multi-disciplinary open access archive for the deposit and dissemination of scientific research documents, whether they are published or not. The documents may come from teaching and research institutions in France or abroad, or from public or private research centers.
L'archive ouverte pluridisciplinaire HAL, est destinée au dépôt et à la diffusion de documents scientifiques de niveau recherche, publiés ou non, émanant des établissements d'enseignement et de recherche français ou étrangers, des laboratoires publics ou privés. 


\section{Epidemiology and clinical presentation of gonorrhoea in England \& Wales: Findings}

from the Gonococcal Resistance to Antimicrobials Surveillance Programme 2001-2006

Valerie Delpech ${ }^{1}$, Iona Martin ${ }^{1}$, Gwenda Hughes ${ }^{1}$, Tom Nichols ${ }^{1}$, Laura James ${ }^{1}$ and Catherine Ison $^{1}$ on behalf of the GRASP steering group.

1. Health Protection Agency Centre for Infections, 61 Colindale Avenue, London NW9 5EQ, UK

Corresponding author:

Professor Catherine Ison

Sexually Transmitted Bacteria Reference Laboratory, Health Protection Agency Centre for Infections,

61 Colindale Avenue,

London NW9 5EQ, UK

Email:Catherine.ison@hpa.org.uk

\section{GRASP Steering Group}

Prof Catherine Ison ${ }^{1}$, Dr Gwenda Hughes ${ }^{1}$ Ms Leah de Souza-Thomas ${ }^{1}$, Dr Stephanie Chisholm, ${ }^{1}$ John Anderson ${ }^{1}$, Elisabeth Maclure ${ }^{1}$, Dr Alan Johnson ${ }^{1}$, Prof George Kinghorn ${ }^{2}$, Dr David Livermore $^{1}$, Dr Rohinton Mulla ${ }^{3}$, Mr Tom Nichols ${ }^{1}$, Dr Angela Robinson ${ }^{4}$, Prof Jonathan Ross ${ }^{5}$, Dr Jim Wade ${ }^{6}$, Dr Hugh Young ${ }^{7}$.

1. Health Protection Agency, Centre for Infections, 61 Colindale Avenue, London NW9 5EQ.

2. Department of Genitourinary Medicine, Royal Hallamshire Hospital, Glossop Road, Sheffield S10 2JF.

3. Luton Microbiology Laboratory, Lewsey Road, Luton LU4 0EP.

4. The Mortimer Market Centre, Camden and Islington NHS Trust, Off Capper Street, London WC1E 6AU.

5. The Whittall Street Clinic, Department of GU Medicine, Whittall Street, Birmingham B4 $6 \mathrm{DH}$.

6. Health Protection Agency South London, King's College Hospital, Denmark Hill, London SE5 9RS.

7. Scottish Bacterial Sexually Transmitted Infections Reference Laboratory, Edinburgh Royal Infirmary, Little France, Edinburgh EH16 4SA.

Word count: 2397

Tables: 1

Key words: Neisseria gonorrhoeae, surveillance, epidemiology 


\section{Key messages:}

1. Data from the Gonococcal Resistance to Antimicrobials Surveillance Programme (GRASP) indicate that in contrast to chlamydial infections, gonorrhoea remains concentrated in specific population groups.

2. Men who have sex with men, especially those that are HIV positive, and young black Caribbean heterosexuals continue to be at particular risk

3. Prevention efforts of proven effectiveness aimed at these groups are urgently required.

4. High re-infection rates and concurrent STIs among cases of gonorrhoea underscores the need for prompt partner notification and treatment. 


\begin{abstract}
Objective: To analyse the enhanced data for gonorrhoea cases in England and Wales collected by the Gonococcal Resistance to Antimicrobials Surveillance Programme (GRASP) to better inform health policy and targeted interventions.
\end{abstract}

Methods: GRASP data obtained annually from sentinel GUM clinics between June to August during 2001-2006 were analysed.

\title{
Results
}

A total of 12,282 cases of gonorrhoea were reported during the study period, with a decline over time primarily in heterosexual patients of black ethnicity. $73 \%$ of women, $47 \%$ of heterosexual men and 22\% of MSM were aged under 25. Most infected women reported a single sexual partner in the previous 3 months, whereas most heterosexual men and MSM reported two or more partners. A history of gonorrhoea was reported by $42 \%$ of MSM, $30 \%$ of heterosexual men, and $20 \%$ of women. Excluding HIV, women were more likely than men to have a concurrent STI at diagnosis, most commonly Chlamydia (50\% vs $27 \%$ p $<0.0005)$.

Rectal gonococcal infections were reported in 35\% and HIV co-infection in $31 \%$ of MSM. Compared to HIV negative MSM, those co-infected with HIV were older (median 35 years vs 28 years) and were more likely to attend a London site (70\% vs $52 \%, \mathrm{p}<0.0005)$; have a concurrent STI ( $28 \%$ vs $20 \%, \mathrm{p}=0.002)$; have a history of gonorrhoea $(66 \%$ vs $36 \%, \mathrm{p}<0.0005)$ and have more sexual partners (average 6.8 vs 4.3 ).

\section{Conclusion}

Gonorrhoea is concentrated within specific groups who are at high risk of repeat infections and concurrent STIs including HIV. Targeted interventions of proven effectiveness are urgently required. 


\section{INTRODUCTION}

In the United Kingdom, infections due to Neisseria gonorrhoeae are predominantly diagnosed and treated free of charge in open-access genitourinary medicine (GUM) clinics[1]. National statistics on gonorrhoea and other sexually transmitted infections (STIs) diagnosed in these GUM clinics are collated by the Health Protection Agency (HPA) in aggregate form via KC60 returns [1]. Gonorrhoea diagnoses fell sharply in the 1980s and early 1990s, largely owing to safer sexual behaviours brought about in response to the HIV epidemic[2].Diagnoses began to rise after 1994, peaked in 2002 and have fallen subsequently. Gonorrhoea remains concentrated in large urban areas, particularly London, with a rate of 157/100,000 population. Rates among men outnumber those among women due to a high number of diagnoses in MSM and because infections in women are more likely to be asymptomatic [1]

Detailed demographic, behavioural and risk information is critical to understanding the epidemiology, informing public health policy, and to evaluating the success or failure of health promotion activities aimed at reducing the transmission of STIs. While the KC60 returns provide useful national trend data on STIs diagnosed at GUM clinics, they contain limited information regarding the risk behaviour of the individuals who acquire infections. To gain a better insight into the epidemiology of gonorrhoea in England and Wales, we analysed the enhanced dataset collected through the Gonococcal Resistance to Antimicrobials Surveillance Programme (GRASP) [3] for the years 2001-2006. Established in 2000, GRASP primarily monitors trends in antimicrobial resistance among gonococcal isolates to inform treatment guidelines [4,5], but also provides detailed epidemiological and behavioural profiles of individuals diagnosed with gonorrhoea at sentinel GUM clinics in England and Wales.

\section{METHODS}

Sites: Twenty-six sentinel GUM clinics and their supporting laboratories in England and Wales take part in the programme each year, nine in London and 17 elsewhere. The clinics outside London were originally selected on the basis of geography, two per Health Region, and the burden of disease, having greater than 100 diagnoses per annum. The Health Regions were however changed in 2002, and the new North East region has only one GRASP site.

Ethics permission was obtained from local regional research committees and from the North West multi-centre research ethics committee. Patients were informed of the study at the participating site through written notices. 


\section{Population and analyses}

All patients clinically diagnosed with a gonorrhoea, and with a corresponding isolate of Neisseria gonorrhoeae obtained at a participating laboratory between the months of June and August for the years 2001-2006 were included. Only one isolate of $N$. gonorrhoeae per patient was tested and where multiple sites were infected an order of preference was assigned (in order: Men: rectal, urethral, any other site; Women: cervical, any other site).

Data were collected using a standard form and included gender, age, sexuality, ethnicity, concurrent STIs at attendance, symptoms, site of infection, previous episodes of gonorrhoea, number of sexual partners over the previous three months within the UK and abroad and therapy prescribed. HIV status has been collected since 2004. Duplicate cases were removed from the dataset if the same patient presented more than once within a 28 -day period. Tests of significance are either by Pearson's chi-squared test or by Fisher's exact test. Proportions were calculated, taking all cases with available information as the denominator, but excluding cases with missing values.

\section{RESULTS}

\section{Trends}

A total of 12,282 individuals were reported to GRASP over the period (2001 to 2006) with just under half $(47 \%)$ of diagnoses reported from London sites. The number of cases reported annually declined from 2513 in 2001 to 1599 in 2006, a 36\% decrease. The proportion of diagnoses among men who have sex with men (MSM) significantly increased from $25 \%$ in 2001 to $39 \%$ in $2006(\mathrm{p}<0.005)$.

\section{Epidemiological and clinical characteristics}

Almost three-quarters (73\%) of cases were men, of whom 40\% (3310/8174) were MSM. Women were younger, with median age of 20 years at diagnosis compared with 25 and 31 years among heterosexual men and MSM respectively.

Diagnoses varied by gender, sexual exposure (men) and ethnicity, with women and MSM most likely to be white, and heterosexual men most likely to be black (Table 1). These aspects however changed over time and, among heterosexuals, there was a striking decline in the proportion of diagnoses among those of black Caribbean ethnicity, declining from $43 \%$ (444) in 2001 to $30 \%$ (142) in 2006 in men and from 205 (32\%) to 68 (21\%) in women. 
The majority of cases were infected at one anatomical site (Table 1) with the cervix the most common site of gonococcal isolation in women (98\%) and the urethra in both heterosexual men (98\%) and MSM (65\%). Rectal and pharyngeal infections were reported in $35 \%$ and $15 \%$ of MSM respectively.

Heterosexual men were most likely to present with symptoms, followed by MSM and then women (Table 1). A history of gonorrhoea was common in all groups, but most common in MSM (Table 1). Women were more likely to have a concurrent STI, diagnosed at the same time as gonorrhoea, than men $(50 \%$ compared with $27 \%, \mathrm{p}<0.0005)$. Chlamydia was the most common concurrent pathogen across all groups (Table 1).

Sex abroad was a relatively small but significant risk factor (Table 1). Among cases with this risk factor, the majority of MSM (65\%) indicated a partner in another western European country, whereas $57 \%$ of the women reported contact in the Caribbean and heterosexual men reported partners in a variety of regions including the Far East (25\%), Caribbean (21\%) and another western European country (21\%).

The average number of sexual partners reported over the previous three months was 1.7 for women, 2.2 for heterosexual men and 4.7 for MSM, with a median of one partner for women and two for both heterosexual men and MSM. The majority of women reported a single sexual partner in the previous 3 months, whereas, more than half of heterosexual men and MSM reported two or more sexual partners (Table 1). Significantly more MSM than heterosexual men reported six or more sexual partners (18\% of MSM vs. $4 \%$ of heterosexual men; $\mathrm{p}<0.0005)$.

HIV status was available for the years 2004-2006. Where available, a positive HIV status was recorded for $31 \%$ of MSM. HIV-co-infected MSM were older at presentation than HIVnegative men (median 35 years vs 28 years), more likely to present at a London site (70\% vs $52 \%, \mathrm{p}<0.0005)$, to have a history of gonorrhoea $(66 \%$ vs $36 \%, \mathrm{p}<0.0005)$ and to have a concurrent STI (28\% vs 20\%, p=0.002). HIV-positive MSM had a higher average number of sexual partners in the three months prior to their gonorrhoea diagnosis (6.8 versus 4.3 for HIVnegative men).

Patients aged $<25$ years compared with those aged $>25$ years 
Seventy-three percent of the infected women, $47 \%$ of the heterosexual men and $22 \%$ of the MSM were under 25 years. The younger women were more likely to have a concurrent STI than older women (55\% vs $36 \%$, p<0.0005), and despite a probable shorter sexual history, given their younger age, up to $20 \%$ reported a history of gonorrhoea, compared with $22 \%$ for older women. Similarly, $37 \%$ of young heterosexual men presented with a concurrent STI and a quarter $(25 \%)$ had a history of gonorrhoea, compared to $27 \%$ and $33 \%$ in older men respectively. The same proportion of young and older MSM had a concurrent STI (21\%). About a quarter (28\%) of young MSM reported a history of gonorrhoea compared with $45 \%$ in older MSM. Numbers of sexual partners reported in the previous three months did not differ by age group in women or men.

\section{DISCUSSION}

GRASP has provided a detailed description of the epidemiology of gonorrhoea in England and Wales and its findings show that many of the infected patients are repeatedly engaging in highrisk sexual behaviours. In particular, the GRASP data confirm the high burden of gonococcal infection in core groups of MSM, particularly those that are HIV-positive, and young heterosexual adults, particularly those with a history of gonorrhoea and those of black Caribbean ethnicity.

Most of the MSM patients were of white ethnicity, predominantly aged between 25-34 years and report multiple sexual partners in the previous three months. One in seven (14\%) probably acquired their infection abroad. The high proportion (31\%) of HIV co-infection is alarming, especially since HIV-positive men were more likely to report previous gonorrhoea and concurrent STI and had a higher average number of sexual partners than HIV-negative men. These findings indicate that HIV-positive men are at higher risk of acquiring further STIs than HIV-negative men. Selection of sexual partners, based on known HIV status (termed 'serosorting'), and choosing not to use a condom are likely to increase the risk of other STIs. High rates of gonococcal rectal infections (35\%) among MSM provide evidence of unprotected receptive anal sex and are of concern, for both HIV positive and negative men. These data are supported by behavioural surveys showing continued high-risk sexual behaviours and inconsistent condom use among MSM, including those that are HIV positive [5-8]. Consequently MSM remain the group most at risk of STIs in the UK [1,10,11]) and internationally [12-14]. There is an urgent need to strengthen prevention efforts in gay men, ensuring targeted interventions for both HIV positive and negative men across all age groups. 
Men who acquired gonorrhoea through heterosexual contact were mostly aged between 20 and 34 years; overall one in three was of black Caribbean ethnicity, though this proportion fell over time. Like MSM, most heterosexual men reported multiple sexual partners in the three months prior to diagnosis and about one in ten probably acquired their infection while abroad. There were marked differences in the characteristics of infected women compared with both heterosexual and homosexual men. Unlike heterosexual men, most women are diagnosed as young adults (three quarters are aged less than 25 years) and most report a single sexual partner in the previous 3 months. A disproportionate number were of black-Caribbean ethnicity or of another black ethnicity. The lower median age at diagnosis of women is likely to reflect patterns of sexual mixing within the heterosexual population. [15]

High re-infection rates (one in five had a previous episode of gonorrhoea) and concurrent infections with another STI (especially chlamydia) is of particular concern across all groups and underscores the need for prompt partner notification and treatment. Furthermore, over half of women were asymptomatic for gonorrhoea indicating a potential reservoir of undiagnosed gonococcal infections. Screening for gonococcal infection performed in young people participating in the National Chlamydia Screening Programme in England [16] in areas of London suggest a high rate of gonorrhoea among those screened [17]. Close monitoring and evaluation of such initiatives, particularly in view of possible limitations of nucleic acid amplification tests (NAATS), are required to inform future guidance in this area.

The over-representation of diagnoses among black Caribbean men and women who acquired their infection heterosexually is striking, given that persons of black Caribbean ethnicity comprise only $1 \%$ of the population of England and Wales [18]. Local studies have previously identified ethnic minorities as being particularly at-risk of gonorrhoea within the inner London area [19-21]. Our findings confirm similar disparities across the country [22,23]. Racial disparities in the incidence of bacterial STIs reported in the United States have been attributed to poor access to quality health services and racial differences in sexual mixing and network patterns [24,25]. Poor access to health care is less likely to play a role in the UK given the availability of universal and free access to sexual health services. Furthermore there have been substantial improvements in access to GUM clinics since it was identified as a major priority area in the National Strategy for Sexual Health and HIV government (20012010) for England [26]. HPA data indicate a rise in the overall percentage of patients seen within 48 hrs at GUM clinics from $48 \%$ in 2004 to $72 \%$ in 2007 (it was $65 \%$ in November 2006 at the end of the study period) [27]. Although no ethnicity data are available, the 
survey was conducted on all patients attending all GUM services over a one-week period and is therefore believed to be representative of all STI attendees. Rather, a high background prevalence of gonorrhoea, relatively infrequent inter-racial sexual mixing, high partner change (males) and frequent travel to or migration to the Caribbean are likely to be contributing factors.

Recent declines in gonorrhoea diagnoses among heterosexuals, and particularly those of blackAfrican ethnicity, are encouraging and reasons for this trend should be explored further. It is possible that improvements in partner notification and a decrease in GUM clinic waiting times have contributed to this decline [28]. The failure of these initiatives to reduce infection rates among MSM may reflect their higher partner change rate $[22,28]$. The decline in gonorrhoea diagnoses in heterosexuals reported in our study is reflected in national statistics. This is in contrast to diagnoses of other STIs, such as chlamydia, genital herpes, warts and HIV, which continue to rise [1]. The often complex clinical presentation of these STIs is likely to make their detection, diagnosis and treatment more challenging than for gonorrhoeal infections.

The failure of these initiatives to reduce infection rates among MSM may reflect their higher partner change rate $[22,28]$. The decline in gonorrhoea diagnoses in heterosexuals reported in our study is reflected in national statistics. This is in contrast to diagnoses of other STIs, such as chlamydia, genital herpes, warts and HIV, which continue to rise [1]. The often complex clinical presentation of these STIs is likely to make their detection, diagnosis and treatment more challenging than for gonorrhoeal infections.

There are several limitations to our study. The 26 sentinel sites participating in the GRASP programme were selected on the basis of high throughput to optimise regional coverage and may not be entirely representative. Furthermore, GRASP primarily collects data from GUM clinics and will therefore miss patients diagnosed in primary care and other settings, although laboratory data indicate that there are few diagnoses is these settings [1] Nevertheless monitoring of gonorrhoea and other STIs in these settings will become increasingly important given shifts towards greater testing of STIs outside of GUM clinics. Greater use of non-culturebased diagnostic methods involving nucleic acid amplification is likely to impact on this trend.

The findings of this study highlight the highly concentrated nature of gonorrhoea presenting at GUM clinics within specific at risk groups, many of whom have reported prior STI infections. This underscores the importance of partner notification and the urgent need for targeted interventions of proven effectiveness. 
Table 1: Epidemiological and behavioural characteristics of persons infected with gonorrhoea in E \&W by gender and male sexual orientation, GRASP, 2001-2006

\begin{tabular}{|c|c|c|c|c|}
\hline Year & Female cases & $\begin{array}{c}\text { Male } \\
\text { heterosexually } \\
\text { Acquired cases }\end{array}$ & $\begin{array}{c}\text { Men who sex } \\
\text { with men } \\
\text { (MSM) } \\
\end{array}$ & Total cases** \\
\hline-2001 & 735 & 1062 & 602 & 2,513 \\
\hline$-\quad 2002$ & 657 & 991 & 515 & 2,309 \\
\hline$-\quad 2003$ & 603 & 889 & 507 & 2,136 \\
\hline-2004 & 554 & 756 & 565 & 2,045 \\
\hline$-\quad 2005$ & 448 & 610 & 518 & 1,680 \\
\hline-2006 & 375 & 556 & 603 & 1,599 \\
\hline Total & 3372 & 4864 & 3310 & 12,282 \\
\hline Characteristic & $\begin{array}{c}\text { Female cases } \\
\%\end{array}$ & $\begin{array}{c}\text { Male } \\
\text { heterosexual } \\
\text { cases \% } \\
\end{array}$ & $\begin{array}{c}\text { MSM cases } \\
\sim \%\end{array}$ & $\begin{array}{c}\text { Total cases } * * \\
\%(\mathbf{n})\end{array}$ \\
\hline Ethnicity & & & & \\
\hline$-\quad$ White $^{\wedge}$ & 50.4 & 38.2 & 88.2 & $56.2(6030)$ \\
\hline - $\quad$ Black Caribbean & 28.0 & 37.4 & 2.6 & $24.6(2643)$ \\
\hline - $\quad$ Black African & 4.2 & 7.6 & 1.6 & $4.9(529)$ \\
\hline - $\quad$ Other Black & 9.3 & 7.5 & 1.2 & $6.1(656)$ \\
\hline - $\quad$ Asian+ & 2.7 & 5.3 & 2.7 & $3.8(407)$ \\
\hline - Other ethnic group & 5.4 & 4.0 & 3.9 & $4.3(465)$ \\
\hline Age in years & & & & \\
\hline$-\quad<19$ & 41.8 & 15.8 & 4.1 & $19.4(2370)$ \\
\hline$-\quad 20-24$ & 31.0 & 31.6 & 17.7 & $27.2(3336)$ \\
\hline$-\quad 25-34$ & 18.8 & 32.5 & 44.2 & $32.2(3941)$ \\
\hline$-\quad 35-44$ & 6.8 & 14.0 & 27.2 & $16.1(1970)$ \\
\hline$-\quad \geq 45$ & 1.6 & 6.1 & 6.9 & $5.2(632)$ \\
\hline Multiple sites infected & 7.1 & 1.5 & 13.7 & $6.6(741)$ \\
\hline History of gonorrhoea & 20.4 & 29.5 & 41.6 & $30.5(3331)$ \\
\hline Concurrent STI (excl HIV) & 49.6 & 31.7 & 20.8 & $33.7(3685)$ \\
\hline - Chlamydia & 37.4 & 26.4 & 10.1 & $24.7(2716)$ \\
\hline - Warts & 2.6 & 1.8 & 1.9 & $2.0(225)$ \\
\hline - Herpes & 1.4 & 0.7 & 0.7 & $0.9(99)$ \\
\hline - Syphilis & 0.4 & 0.7 & 2.9 & $1.3(138)$ \\
\hline Symptomatic & 59.1 & 90.4 & 74.2 & $77.2(8494)$ \\
\hline Sex abroad in last 3 months & 6.0 & 9.8 & 14.1 & $10.0(1109)$ \\
\hline \multicolumn{5}{|l|}{$\begin{array}{l}\text { Number of sexual partners } \\
\text { in last } 3 \text { months }\end{array}$} \\
\hline$-\quad 0-1$ & 68.1 & 34.7 & 24.7 & $41.0(4514)$ \\
\hline$-\quad 2-5$ & 31.1 & 61.1 & 57.5 & $51.9(5729)$ \\
\hline$-6-10$ & 0.3 & 3.3 & 9.4 & $4.2(469)$ \\
\hline$-\quad 11+$ & 0.4 & 0.9 & 8.5 & $1.9(326)$ \\
\hline - Range & $0-300$ & $0-98$ & $0-255$ & $0-300$ \\
\hline - Median & 1 & 2 & 2 & 2 \\
\hline
\end{tabular}

** includes men of unknown sexual orientation

$\wedge$ White ethnicity includes white British, white Irish and white other

+ Asian includes Indian, Pakistani, Bangladeshi, Chinese and other Asian 


\section{REFERENCES}

1. The UK collaborative group for HIV and STI surveillance. Testing Times. HIV and other sexually transmitted infections in the United Kingdom: 2007. London. Health Protection Agency Centre for Infections. November 2007.

2. Nicoll A, Hughes G, Donelly M et al. Assessing the impact of national anti-HIV sexual health campaigns: trends in transmission of HIV and other sexually transmitted infections in England. Sex Transm Infect 2001;77:242-7

3. Paine TC, Fenton KA, Herring A, et al. GRASP: a new national sentinel surveillance initiative for monitoring gonococcal antimicrobial resistance in England and Wales. Sex Transm Infect. 2001;77:398-401

4. Fenton KA, Ison C, Johnson AP et al. Ciprofloxacin resistance in Neisseria gonorrhoeae in England and Wales in 2002. Lancet. 2003:361:1867-1869.

5. National guideline on the diagnosis and treatment of gonorrhoea in adults 2005 . Clinical Effectiveness Group (BASHH, British Association of Sexual Health and HIV) http://www.bashh.org/guidelines (accessed 04/11/2008).

6. Dodds JP, Nardone A, Mercey DM et al. Increase in high risk sexual behaviour among homosexual men, London 1996-8: cross sectional, questionnaire study. BMJ. 2000; 32:1510-1.

7. Johnson AM, Mercer CH. Erens B, et al. Sexual behaviour in Britain: partnerships, practices, and HIV risk behaviours. Lancet. 2001; 358:1835-42.

8. Hart GJ, Williamson LM. Increase in HIV sexual risk behaviour in homosexual men in Scotland, 1996-2002: prevention failure? Sex Transm Infect. 2005;81:367-72.

9. Elford J, Bolding G, Davis M, et al. Trends in sexual behaviour among London homosexual men 1998-2003: implications for HIV prevention and sexual health promotion. Sex Transm Infect. 2004;80:451-4 
10. Mercer $\mathrm{CH}$, Fenton KA, Copas AJ et al. Increasing prevalence of male homosexual partnerships and practices in Britain 1990-2000: evidence from national probability surveys. AIDS 2004;18:1453-1458.

11. Fenton KA, Mercer $\mathrm{CH}$, Johnson AM et al.. reported sexually transmitted disease clinic attendance and sexually transmitted infections in Britain: prevalence, risk factors, and proportionate population burden. J Infect Dis. 2005;191 (suppl 1):S27-S191.

12. Troung HM, Kellogg T, Klausner JD et al. Increases in sexually transmitted infections and sexual risk behaviour without a concurrent increase in HIV incidence among men who have sex with men in San Francisco: a suggestion of HIV serosorting? Sex Transm Infect. 2006;82:461-6

13. Marcus U, Bremer V, Hamouda $\mathrm{O}$ et al. Understanding recent increases in the incidence of sexually transmitted infections in men who have sex with men: changes in risk behaviour from risk avoidance to risk reduction. Sex Trans Dis. 2006;33:11-17

14. Van Rijckevorsel GG, Sonders GJ, Bovee LP et al, Trends in Hepatitis A, B, and Shigellosis compared with gonorrhoea and syphilis in men who have sex with men in Amsterdam, 1992-2006. Sex Transm Dis. 2008 Jul 31 (Epub ahead of print).

15. Choudhury B, Risley CL, Ghani AC et al. Identification of individuals with gonorrhoea within sexual networks: population based study. Lancet Infect Dis 2006;368: 139-146.

16. http://www.statistics.gov.uk/cci/nugget.asp?id=273

17. LaMontagne DS, Fenton KA, Randall S et al. Establishing the National Chlamydia Screening Programme in England: results from the first full year of screening. Sex Transm Infect. 2004;80:335-41

18. Rao GG, Bacon L, Evans J, et al.. Prevalence of Neisseria gonorrhoeae infection in young subjects attending community clinics in South London. Sex Transm Infect $2008 ; 84: 117-21$ 
19. Low N, Daker-White G, Barlow D, Pozniak AL. Gonorrhoea in inner London: results of a cross sectional study. BMJ. 1997; 314:1719-23.

20. Low N, Sterne JE, Barlow D. Inequalities in rates of gonorrhoea and chlamydia between black ethnic groups in south east London: cross sectional study. Sex Transm Infect. 2001;77:15-20.

21. Lewis DA, Bond M, Butt KD, et al One-year survey of gonococcal infection seen in the genitourinary medicine department of a London district general hospital. Int J STD AIDS. 1999;10:588-594.

22. Shahmanesh M, Gayed S, Ashcroft M et al. Geomapping of chlamydia and gonorrhoea in Birmingham. Sex Transm Infect. 2000;76:268-72

23. Hughes G, Nichols T, Rogers P, Kinghorn G, Mercey D, Thin N. Re-infection with gonorrhoea: analysis of risk factors from a retrospective cohort study. MSSVD / SSGM Spring Meeting Oslo, Norway, 15-18 May 2002

24. Wasserheit JN, Aral S. The dynamic topology of sexually transmitted disease epidemics: implications for prevention strategies. J. Infect. Dis. 1998; 174:S201-213.

25. Farley TA, Kahn RH, Johnson G, Cohen DA. Strategies for syphilis prevention findings from surveys in a high-incidence area. Sex. Transm. Dis. 2000;27:305-310

26. Department of Health: Better prevention, better services, better sexual health - The national strategy for sexual health and HIV accessed on 15 Feb 2009 at http://www.dh.gov.uk/en/Publicationsandstatistics/Publications/PublicationsPolicyAnd Guidance/DH 4003133

27. Health Protection Agency's Waiting Times for Genitourinary Medicine clinics audit: Results from August 2007 Audit, accessed on 15 Feb 2009 at http://www.hpa.org.uk/web/HPAwebFile/HPAweb C/1194947361607

28. Hughes G, Leong G, Ward H, Hippisley-Cox J, Ison C. Is gonorrhoea under control in England? International Society for STD Research, Seattle July 29 - August 12007. 


\section{Contributions of authors}

VD, CI GH have been involved with the supervision of GRASP and IM has been involved with the testing of samples and supervision of the laboratory work. TN, IM, VD, LJ undertook data analysis for the manuscript. TN has maintained the dataset since 2000 and performed yearly analyses. VD, IM, CI and GH were responsible for the drafting and editing of the manuscript. All authors have seen and approved the final version.

\section{Conflict of interest}

The authors state that there are no conflicts of interest.

\section{Source of funding}

GRASP has been funded totally (2000-2004) and partially (2005-2007) by the Department of Health (London). The views expressed in the publication are those of the authors and are not necessarily those of the UK Department of Health

\section{Acknowledgements}

We thank Kevin Fenton, who established GRASP, obtained funding and supervised it from 2000-2003, Tom Paine, Elizabeth Rudd and Leah De Souza, GRASP co-ordinators, and Alan Herring and Andrew Turner and all staff who performed susceptibility testing at Genitourinary Infections Reference Laboratory, Bristol, Department of Medical Microbiology, Imperial College London and the Health Protection Agency Centre for Infections. We thank all GRASP collaborating GUM clinics and clinicians and the microbiology laboratories for submitting samples for GRASP and providing clinical data. We thank the Scottish Bacterial Sexually Transmitted Infections Reference Laboratory (SBSTIRL) and particularly Dr Helen Palmer for enabling and participating in the twice yearly quality assurance exchange.

The Corresponding Author has the right to grant on behalf of all authors and does grant on behalf of all authors, an exclusive licence (or non exclusive for government employees) on a worldwide basis to the BMJ Publishing Group Ltd to permit this article (if accepted) to be published in STI and any other BMJPGL products and sub-licences such use and exploit all subsidiary rights, as set out in our licence 


\section{COLLABORATING CENTRES}

EAST MIDLANDS: Northampton: Dr Minassian, Department of Microbiology, Dr Riddell Department of GU Medicine, Northampton General Hospital. Nottingham: Dr Boswell, Nottingham Microbiology Laboratory, University Hospital Queens Medical Centre; Dr Bignell, Department of GU Medicine, Nottingham City Hospital.

EAST of ENGLAND: Cambridge: Dr Farrington, HPA East of England Cambridge Laboratory \& Dr Carne, Department of GU Medicine, Addenbrooke's NHS Trust. Luton: Dr Mulla, Luton Microbiology Laboratory, Dr Balachandran, Department of GU Medicine, Luton \& Dunstable Hospital.

LONDON: Charing Cross: Dr Azadian, Department of Microbiology, Chelsea and Westminster Hospital; Dr McLean, The West London Centre for Sexual Health, Charing Cross Hospital; Dr McOwan, The Victoria Clinic; Dr Boag, John Hunter Clinic, St Stephen's Centre, Chelsea and Westminster Hospital. Homerton: Dr Claxton, Department of Medical Microbiology, \& Dr Nathan, Department of GU Medicine, Homerton Hospital. Kings: Ms M Graver, HPA South London, \& Dr Tenant-Flowers, The Caldecot Centre, King's Healthcare NHS Trust.St George's: Dr Holliman, Department of Medical Microbiology, \& Dr Hay, Department of GU Medicine, St George's Hospital. St Mary's: Dr Jepson, Department of Bacteriology, \& Dr Greene, Jefferiss Wing Centre for Sexual Health, St Mary's Hospital. UCH: Dr Morris Jones, Microbiology Laboratory \& Dr Robinson, The Mortimer Market Centre. University College London Hospitals. Woolwich: Dr Bragman, Department of Microbiology, \& Dr Russell, Trafalgar Clinic for Sexual Health, Queen Elizabeth Hospital.

NORTH EAST: Newcastle: Dr Magee, HPA North East Newcastle Laboratory, \& Dr Sankar, Department of GU Medicine, Newcastle General Hospital.

NORTH WEST: Liverpool: Dr Neal, Medical Microbiology Department, \& Dr Carey, Department of GU Medicine, Royal Liverpool Hospital. Manchester: Dr Qamruddin, Department of Microbiology, \& Dr Sukthankar, Manchester Centre for Sexual Health, Manchester Royal Infirmary.

SOUTH EAST: Brighton: Dr Paul, Brighton Microbiology Department \& Dr Dean, Department of GU Medicine, The Royal Sussex County Hospital. Reading: Dr Stacey, Microbiology Department, \& Dr Wildman 'Florey Unit' Department of GU Medicine, Royal Berkshire Hospital.

SOUTH WEST: Bristol: Dr Spencer, HPA South West, \& Dr Horner, Milne Sexual Health Centre, Bristol Royal Infirmary. Gloucester: Dr Logan, Gloucester Microbiology Laboratory, \& Dr Sulaiman, Department of GU Medicine, Gloucestershire Royal Hospital.

WALES: Cardiff: Dr Hosein, NPHS Microbiology Cardiff, \& Dr Birley, Department of GU Medicine, Cardiff Royal Infirmary. Newport: Dr Kubriak, Department of Clinical Microbiology \& Infection Control, \& Dr Das, Department of GU Medicine, Royal Gwent Hospital.

\section{WEST MIDLANDS}

Birmingham: Dr Gill, Department of Clinical Microbiology, Queen Elizabeth Hospital \& Dr Ross, Whittall Street Clinic, Department of GU Medicine. Wolverhampton: Dr Jones, 
Department of Microbiology, \& Dr Fernando, The Fowler Centre for GU Medicine, New Cross Hospital.

YORKSHIRE \& HUMBERSIDE: Leeds: Dr Gascoyne-Binzi, Department of Microbiology, $\&$ Dr Clarke, Centre for Sexual Health, Leeds General Infirmary. Sheffield: Dr Zadik, Sheffield Microbiology Laboratory, Northern General Hospital; Dr Kinghorn, Department of GU Medicine, Royal Hallamshire Hospital 
